\title{
ARTICLE OPEN \\ Dynamics of coarse and fine particle exposure in transport microenvironments
}

\author{
Prashant Kumar $\mathbb{D}^{1}$, loar Rivas ${ }^{1}$, Anant Pratap Singh ${ }^{1,2}$, Vikas Julius Ganesh ${ }^{1,3}$, Monirupa Ananya ${ }^{1,3}$ and H. Christopher Frey ${ }^{4}$
}

A significant fraction of daily personal exposure to air pollutants occurs during commuting in transport microenvironments (TMEs). We carried out systematic mobile monitoring on a pre-defined route to assess personal exposure levels of particulate matter (PM) in four TMEs (bus, car, cycle and walk). Measurements were made during morning peak (MP), afternoon off-peak (OP) and evening peak (EP) hours in a typical UK town, Guildford. The objectives were to quantify the real-time exposure to fine and coarse particles, identify the factors influencing their spatiotemporal variation and estimate the respiratory deposition doses (RDD). The mean $\mathrm{PM}_{10}$ concentrations were $90 \pm 63,23 \pm 9,14 \pm 17$ and $63 \pm 76 \mu^{-3} \mathrm{~m}^{-3}$ for bus, car, cycle and walk modes, respectively. The average ratios of $\mathrm{PM}_{2.5} / \mathrm{PM}_{10}$ were $0.32,0.90,0.67$ and 0.36 for bus, car, cycle and car journeys, respectively. The mean concentrations of coarse particles $\left(\mathrm{PM}_{2.5-10}\right)$ followed the trend: bus $>$ walk $>$ cycle $>$ car. In contrast, mean concentrations of submicron $\left(\mathrm{PM}_{1}\right)$ and fine particles $\left(\mathrm{PM}_{2.5}\right)$ were usually high in the car while lowest for cyclists. RDD depend on the physical activity, particle size distribution and thus deposited fraction are not always proportional to the ambient concentration. RDD for coarse particles were largest for the walk mode $\left(56 \pm 14 \mu \mathrm{g} \mathrm{h}^{-1}\right)$, followed by buses $\left(31 \pm 2 \mu \mathrm{g} \mathrm{h}^{-1}\right)$, cycle $\left(12 \pm 3 \mu \mathrm{g} \mathrm{h}^{-1}\right)$ and cars $\left(1.2 \pm 0.3 \mu \mathrm{g} \mathrm{h}^{-1}\right)$. The corresponding RDD of fine particles were comparable for both walk $\left(5.5 \pm 0.3 \mu \mathrm{g} \mathrm{h}^{-1}\right)$ and cycle $\left(5.1 \pm 1.2 \mu \mathrm{g} \mathrm{h}^{-1}\right)$, followed by bus $\left(4.1 \pm 0.7 \mu \mathrm{g} \mathrm{h}{ }^{-1}\right)$ and $\operatorname{car}\left(2.0 \pm 0.2 \mu \mathrm{g} \mathrm{h}^{-1}\right)$. Car mode experienced both the least concentrations and RDD for coarse particles. It also had the lowest RDD for fine particles despite high concentrations. Physical activity of car commuters is modest compared with walking and cycling, which makes the rank ordering of RDD different than those of exposure concentrations. Hence the management of commuting exposures should consider potential dose and not just exposure concentration for curtailing adverse health effects related to commuting. RDD for pedestrian and cycle modes were not the lowest among the measured modes but opportunities such as an increased distance between the heavily trafficked roadways and pedestrians/cyclists should be considered in urban planning to reduce potential doses.

npj Climate and Atmospheric Science (2018)1:11; doi:10.1038/s41612-018-0023-y

\section{INTRODUCTION}

Road vehicles are by far the main contributors to air pollution in cities. $^{1,2}$ Most metropolitan cities around the world experience periods of elevated pollutant levels, which surpass various international air quality standards. ${ }^{3,4}$ Vehicular emissions occur close to the ground level where both vehicles and urban commuters co-exist. ${ }^{5}$ Commuting in urban environments leads to high exposure to air pollutants. ${ }^{6}$ Commuting exposures depend on the choice of transport mode, time of day, route and fuel type. ${ }^{7,8}$ Furthermore, particulate matter (PM) concentrations inside the vehicle vary differently to those in outdoor ambient environments. ${ }^{9,10}$ Therefore, controlling commuting exposure is challenging, particularly in highly populated and polluted cities.

The ambient concentrations of airborne particles with aerodynamic diameter $\leq 10 \mu \mathrm{m} \quad\left(\mathrm{PM}_{10}\right)$ and $\leq 2.5 \mu \mathrm{m} \quad\left(\mathrm{PM}_{2.5}\right)$ are regulated through ambient air quality standards. $\mathrm{PM}_{2.5}$ are fine particles that also include the fraction of particles below $1 \mu \mathrm{m}$ (i.e., $\left.\mathrm{PM}_{1}\right)$. Particles between 2.5 and $10 \mu \mathrm{m}\left(\mathrm{PM}_{2.5-10}\right)$ are coarse particles. ${ }^{11}$ Contributions to coarse and fine particles come from different sources. Some portion of each size range is from primary emissions while other portions are secondary particles that are formed in the atmosphere, including secondary organic aerosols that can be traced to volatile organic carbon emissions from vehicles. ${ }^{12}$ Coarse particles are usually dominated by non-exhaust sources such as road abrasion, brake and tyre wear while fine particles mainly come from fuel combustion in engines. ${ }^{13,14}$

The association between traffic-related air pollution and human health is well documented from both epidemiological and toxicological studies. ${ }^{15,16}$ Epidemiological studies have found significant associations between exposure to airborne particles and cardiovascular and respiratory diseases. ${ }^{17-19}$ Ambient PM has been ranked as the ninth risk factor for global burden of disease ${ }^{20}$ and classified as group 1 carcinogenic to humans. ${ }^{21}$

Exposure is the contact of a pollutant with the outer boundary of the body. Exposure takes into account the concentration of a pollutant in the air at the point of contact with a person. Exposure assessment also takes into account the frequency and duration of contact, such as travel time. However, the health risk from exposure also depends on how much pollution penetrates into the body. For example, breathing rates while walking or cycling

\footnotetext{
${ }^{1}$ Global Centre for Clean Air Research (GCARE) Department of Civil and Environmental Engineering Faculty of Engineering and Physical Sciences, University of Surrey, Guildford GU2 7XH, UK; ${ }^{2}$ Department of Civil Engineering, Indian Institute of Technology Roorkee, Uttarakhand 247667 , India; ${ }^{3}$ Department of Civil Engineering Saveetha School of

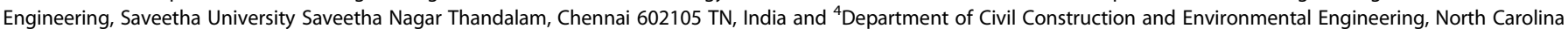
State University, Campus Box 7908, Raleigh, NC 27695-7908, USA

Correspondence: Prashant Kumar (P.Kumar@surrey.ac.uk)
}

Received: 28 September 2017 Revised: 20 March 2018 Accepted: 23 March 2018

Published online: 03 June 2018 
are likely to be considerably greater than those in-car or bus due to the higher level of physical activity. ${ }^{22}$ Respiratory lung deposition doses (RDD) are therefore better indices than merely exposure concentration for assessing health risk and their relative comparison during different modes of commuting. Past studies affirm such a deposition to be three or more times greater under moderate activity than when at rest. ${ }^{23}$

Because on-road and roadside pollutant concentrations can be high during peak periods, commuters may gain a significant proportion of their daily pollutant exposure when in traffic even though such individuals travel for no more than $6-8 \%$ of the daily time. ${ }^{24}$ PM concentration usually peaks during the morning commuting hours because of lower mixing height coupled with peak traffic volume. Congestion increases in-vehicle exposure duration and is associated with emissions hotspots related to repeated vehicle accelerations. ${ }^{6,25-28}$ For instance, as little as $2 \%$ of commuting time spent in the car at traffic intersections can contribute as high as $\sim 25 \%$ of total commuting exposure in certain situations. ${ }^{10}$

Active transport (cycling and walking) is beneficial to health due to increased physical activity. However, it is also associated with increased inhalation rate due to physical activity, which increases RDD. ${ }^{29}$ For example, even though some cyclists experience low concentrations of PM, they have significant potential dose when inhalation rates and trip duration are taken into consideration. ${ }^{30}$ Proximity to motorised traffic is associated with higher cyclist exposure concentrations. ${ }^{31,32}$ Moreover, PM exposures for pedestrians and cyclists are higher on high-traffic routes than on lowtraffic routes. ${ }^{33,34}$ Nonetheless, contemporary studies have found that the health benefits of walking and cycling outweigh the negative consequences and, hence, should be encouraged. ${ }^{35}$

A number of studies have assessed the air pollution exposure of urban dwellers under different transport microenvironments (TMEs) such as cars, ${ }^{10,36,37}$ buses, $^{38,39}$ trains $^{40-42}$ and cycles. ${ }^{43,44}$ Particles of different sizes originate from different sources. Thus, being able to apportion exposures by particle size in different TMEs can be helpful in targeting exposure mitigation to those sources that are the most influential. Furthermore, there are few evaluations of exposure apportionment to particles in transport modes based on particle size, as seen from the summary of relevant studies in Table 1 . In addition, exposure estimate databases for TMEs are yet inadequate. Findings of the current study could benefit in validating exposure models, evaluating the risk-benefit of active physical activity modes (e.g., walk and cycle) $)^{35}$ and developing strategies to control the dominant factors for increased exposure in various TMEs.

Quantification of personal exposure to different PM fractions in different transport modes is therefore an essential first step towards identifying the most effective strategies for reducing exposure. Towards this broader goal, we carried out a systematic investigation of exposure concentrations and RDD for four transport modes (bus, car, cycle and walk). The objectives were to (i) compare fine and coarse particle exposure concentrations among transport modes and for different times of day; (ii) assess the real-time RDD of fine and coarse particles during peak and offpeak (OP) periods; and (iii) identify the factors that influence the temporal variability of particles in different TMEs.

\section{RESULTS}

Overall PM concentration during mobile measurements

Figure 1 shows the concentrations of PM size fractions in four commuting modes, with Table 2 showing their detailed summary. The widest range of variability in $\mathrm{PM}_{10}$ mass concentrations was observed during walk mode $\left(1.2-975 \mathrm{\mu g} \mathrm{m}^{-3}\right)$, followed by cycle $\left(1.4-899 \mathrm{~g} \mathrm{~m}^{-3}\right)$, buses $\left(2.6-717 \mu \mathrm{g} \mathrm{m}^{-3}\right)$ and car $(6.9-169 \mu \mathrm{g}$ $\mathrm{m}^{-3}$ ). Irrespective of the time of the day, average $\mathrm{PM}_{10}$ concentrations have the following trend: buses $>$ walk $>$ car $>$ cycle (Table 2).

Average fine and coarse particles have a different trend (Fig. 1). For fine particles, the trend in average concentration was bus $>$ car $>$ walk $>$ cycle (Fig. 2). Fine particles in the bus and walk modes were time-dependent. For example, concentrations were lower for walk mode than for buses during the morning peak (MP) and evening peak (EP) periods, whereas higher concentrations in walk mode during the OP period. $\mathrm{PM}_{1}$ was always highest for car mode and lowest for cycle mode. The concentration trend of $\mathrm{PM}_{1}$ in the bus and walk modes was similar to that of $\mathrm{PM}_{2.5}$. For coarse particles, the trend was bus $>$ walk $>$ cycle $>$ car (Fig. 2). Besides the infiltration through the bus envelope and, especially, the entrance of outdoor particles during the natural ventilation periods when the doors were open, the highest concentrations in buses may also be affected by high rates of re-suspension of particles due to inflow and outflow of travellers at bus stops. ${ }^{27,34,42,45}$ Concentrations of coarse particles in the car mode were comparable during the MP, OP and EP periods (Fig. 2). The ratio of in-cabin to ambient particles is a function of whether windows are open, and, if windows are closed, whether air is recirculated or there is fresh air intake from the heating, ventilation, and air conditioning (HVAC) system..$^{10,46}$ The lowest concentrations in the car with respect to the rest of modes could be explained by the hindered entrance of outdoor sourced pollutants to the cabin owing to the closed windows. Therefore, infiltration of outdoor particles was expected to be low. Natural ventilation was absent, but mechanical ventilation was forced through the activation of air conditioning. Besides the hindered infiltration by closed windows, the lowest concentrations in the car could also be explained by an efficient removal of coarse particles compared with fine particles by the air conditioning filtration system. ${ }^{23,37}$ However, the low concentrations observed in the cycle mode, even less than the walk mode, could be attributable to forced de-routing on some occasions from busy traffic to quiet areas due to roads work during some runs. In addition, the concentrations usually decay exponentially with height in near-road environments, ${ }^{47,48}$ the relatively higher sampling height during cycle measurements may have made some contributions to the differences. The differences in meteorological conditions and traffic volume were trivial during the walk (February/March) and cycle (March/April) measurements and hence a modest effect of dispersion conditions could be expected to contribute to concentration differences.

Comparison of the concentrations during different time periods revealed that the $\mathrm{PM}_{1}$ and $\mathrm{PM}_{2.5}$ concentrations exhibited a similar trend in each mode: EP > MP > OP in bus and cycle modes; MP > $\mathrm{EP}>\mathrm{OP}$ in car; and MP $>\mathrm{OP}>\mathrm{EP}$ in walk mode (Table 2). The trend for coarse particles was different in all modes: MP > EP > OP in bus; $\mathrm{MP}>\mathrm{EP} \approx \mathrm{OP}$ in cycle; $\mathrm{EP} \approx \mathrm{OP}>\mathrm{MP}$ in car; and $\mathrm{EP}>\mathrm{OP}>\mathrm{MP}$ in walk mode. Despite high traffic volume, previous studies have shown lower coarse particles in comparison with fine particles during morning periods during the walk, owing to the wetness of pavement due to overnight dew. ${ }^{49}$ The walk and car modes followed a similar trend; EP periods had higher concentrations of coarse particles than those in MP and OP periods (Table 2). The bus and cycle modes showed an opposite trend with higher concentrations of coarse particles during MP and EP compared with OP periods (Table 2), presumably because of high resuspension in these TMEs. Fine particle concentrations were always lower in all modes during OP versus MP and EP periods. These lower concentrations could be attributed to lower traffic volume during $\mathrm{OP}$ periods and relatively better dispersion conditions compared with EP/MP periods. ${ }^{47}$ 


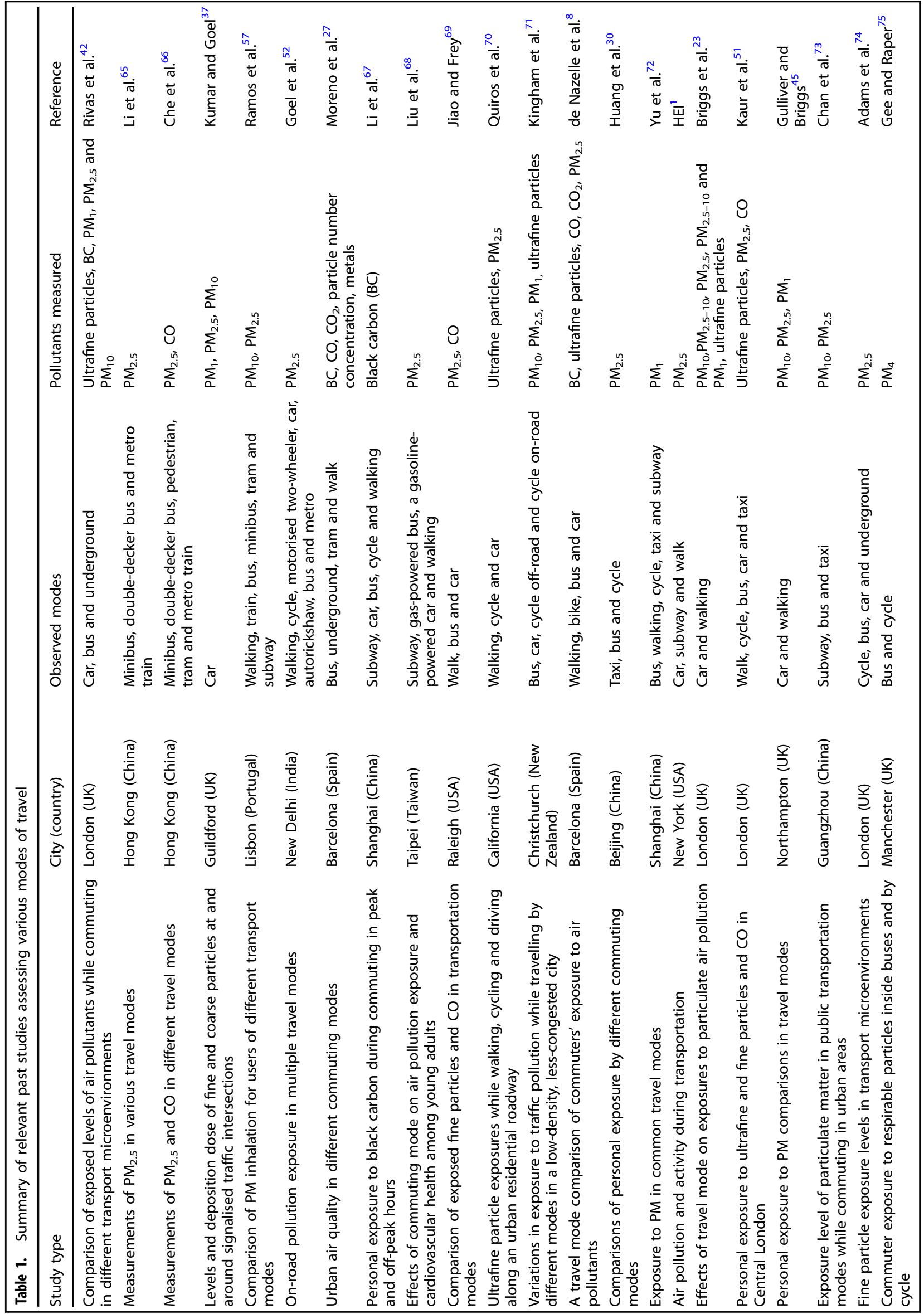



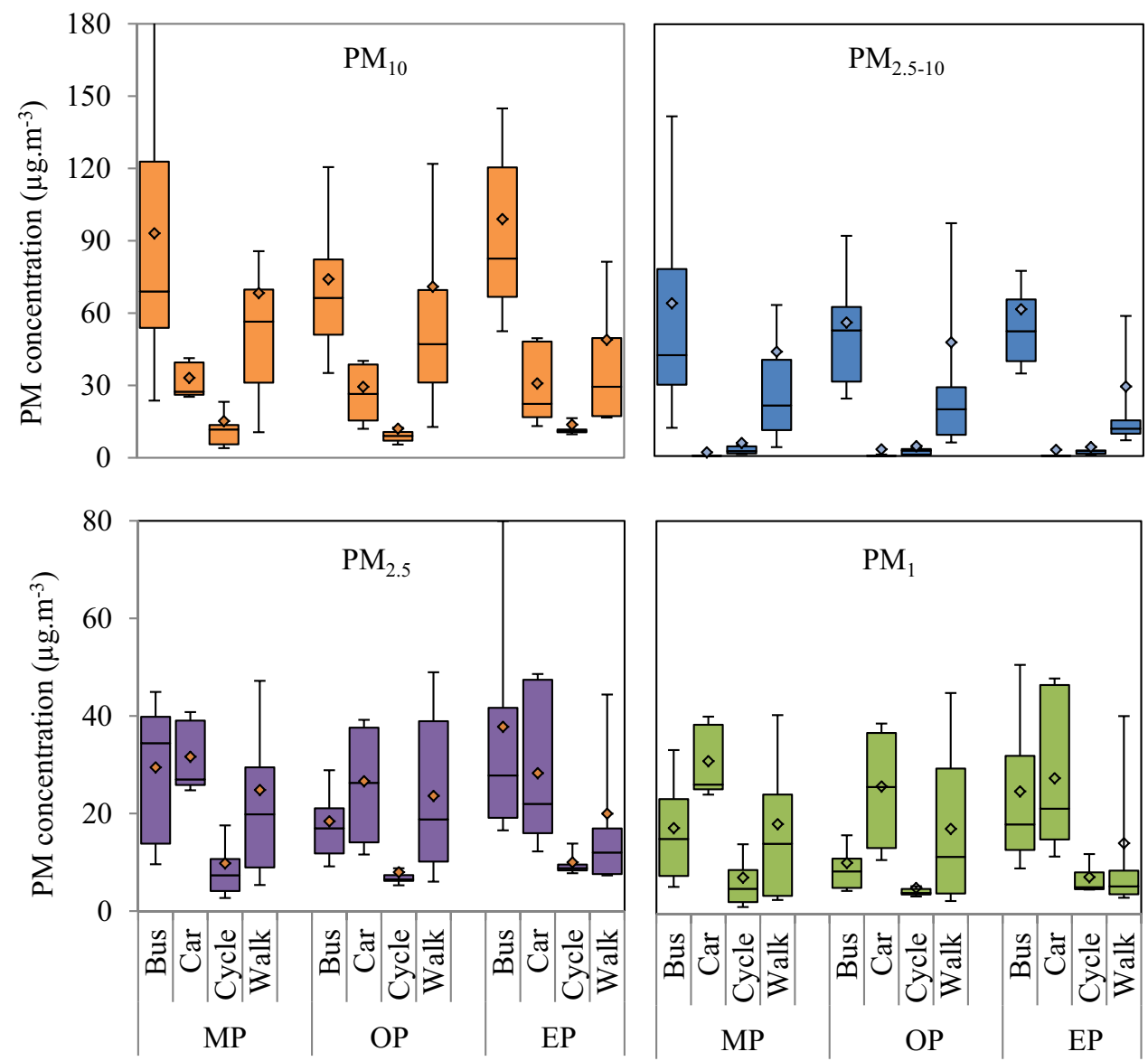

Fig. 1 Concentrations of different PM fractions during morning (MP), off-peak (OP) and evening hours (EP) for the studied commuting modes. The diamond symbols refer to the arithmetic mean concentrations while the median values are shown by horizontal lines within the bars

Table 2. Descriptive statistics for each of the modes of travel by time span and overall; MP, OP and EP refer to morning peak, midday offpeak and evening peak, respectively

\begin{tabular}{|c|c|c|c|c|}
\hline Mode & Time of Day & $\begin{array}{l}\mathrm{PM}_{10} \\
\text { Mean (SD) }\end{array}$ & $\begin{array}{l}\mathrm{PM}_{2.5} \\
\text { Mean (SD) }\end{array}$ & $\begin{array}{l}\mathrm{PM}_{1} \\
\text { Mean (SD) }\end{array}$ \\
\hline \multirow[t]{3}{*}{ Bus } & MP & $93(78)$ & $29(19)$ & $18(11)$ \\
\hline & OP & $79(51)$ & $18(10)$ & $9(5)$ \\
\hline & EP & $115(61)$ & $53(31)$ & $35(18)$ \\
\hline \multirow[t]{3}{*}{ Car } & MP & $33(8)$ & $32(7)$ & $31(7)$ \\
\hline & OP & $29(13)$ & $27(11)$ & $26(11)$ \\
\hline & EP & $31(16)$ & $28(15)$ & $28(15)$ \\
\hline \multirow[t]{3}{*}{ Cycle } & MP & $15(17)$ & $10(7)$ & 7 (6) \\
\hline & $\mathrm{OP}$ & $12(20)$ & $8(9)$ & $5(6)$ \\
\hline & EP & $14(13)$ & $10(4)$ & $8(3)$ \\
\hline \multirow[t]{3}{*}{ Walk } & MP & 72 (124) & $25(22)$ & $18(16)$ \\
\hline & $\mathrm{OP}$ & 73 (102) & $24(18)$ & $17(16)$ \\
\hline & EP & $50(65)$ & $20(18)$ & $14(18)$ \\
\hline
\end{tabular}

Fractional contributions of different-sized PM in TMEs

The absolute and fractional contributions of different-sized PM in studied TMEs are shown in Fig. 3a, b. The average total PM mass concentrations, based on the sum of $\mathrm{PM}_{1}, \mathrm{PM}_{1-2.5}$ and $\mathrm{PM}_{2.5-10}$ size

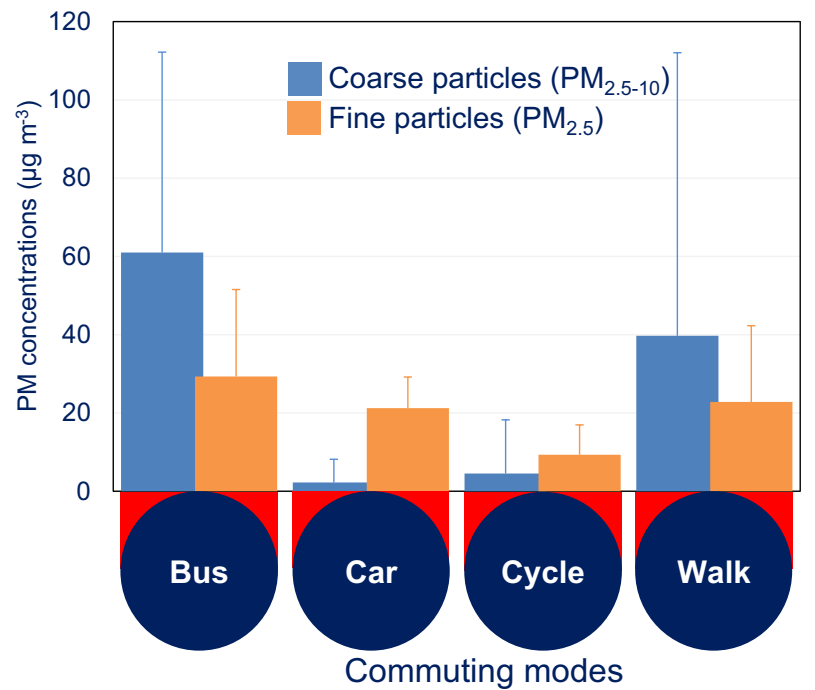

Fig. 2 Average concentrations of coarse and fine particles over the three time periods for commuting modes. The images used are copyright free under the creative common licence (extracted using the Microsoft PowerPoint). Only positive standard deviation values are added to maintain the clarity of the figure

ranges, are clearly greater for bus and walk modes than for car and cycle modes. However, the bus and walk mode total concentrations are dominated by the larger $\mathrm{PM}_{2.5-10}$ size fraction. The fraction of particles that penetrate to the bronchioles and 

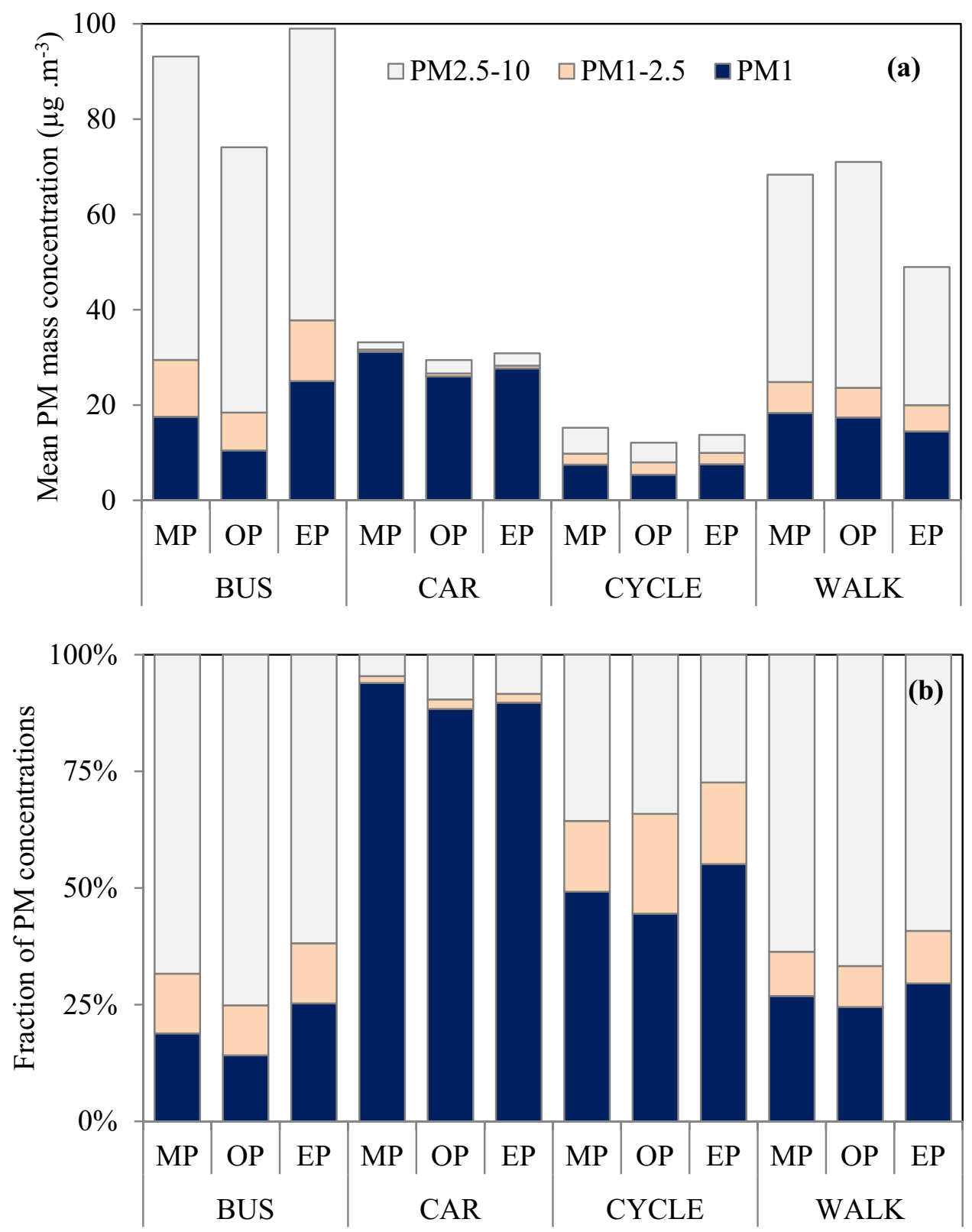

Fig. 3 a Absolute and $\mathbf{b}$ fractional contributions of average PM mass concentrations

alveoli is smaller for the larger-sized particles. The smaller-sized particles, such as $\mathrm{PM}_{1}$ and $\mathrm{PM}_{1-2.5}$, are therefore typically of more health concern. In this regard, the bus, car and walk modes are approximately similar, with $\mathrm{PM}_{2.5}$ mass concentrations ranging from approximately 20 to $40 \mathrm{\mu g} \mathrm{m}^{-3}$, depending on the time of day. There is less variability by time of day for the car and walk modes than for the bus mode. The cycle mode clearly has lower total $\mathrm{PM}$ and $\mathrm{PM}_{2.5}$ mass concentrations than any other mode, regardless of time of day. The car and cycle modes have a relatively little total mass contribution from coarse particles.

The $\mathrm{PM}_{1} / \mathrm{PM}_{2.5}$ ratio was nearly identical $(\approx 0.73)$ for cycle and walk modes. Usually smaller the size of particles, more risk such particles poses to human health. About two-third of $\mathrm{PM}_{2.5}$ being $\mathrm{PM}_{1}$ clearly suggest exposure to such high health-damaging particles. The similarity in the particle size fractions coupled with the differences in exposure concentration implies that the cyclists were exposed to more diluted particles than were the pedestrians. However, the $\mathrm{PM}_{2.5} / \mathrm{PM}_{10}$ ratio of the cycle mode $(0.68 \pm 0.04)$ was different from the walk mode $(0.37 \pm 0.04$; Fig. $3 b)$. The coarse particles, predominantly resulting from re-suspension of dust and tyre wear $^{37}$ in near-road environments, contain larger settling velocity compared with their smaller counterparts. A distinct reasoning was unavailable but the differences in height of measurements may have partly attributed to higher coarse PM exposure to pedestrians versus cyclists.

Fine particles dominate $\left(\mathrm{PM}_{2.5} / \mathrm{PM}_{10} \approx 90 \%\right)$ the PM concentrations in car mode. The windows were closed (low infiltration) and air conditioning system was on (removing more efficiently coarse particles) during our car measurements (Description of travel modes). Coarse particles are more efficiently filtered out by the air conditioning system of the car compared to fine particles, ${ }^{23,42,50}$ explaining the relatively low fraction of coarse particles inside the car.

Normalised PM mass concentrations

We normalised the MP, OP and EP concentrations measured on cycle, car and bus modes with respect to those observed in the 


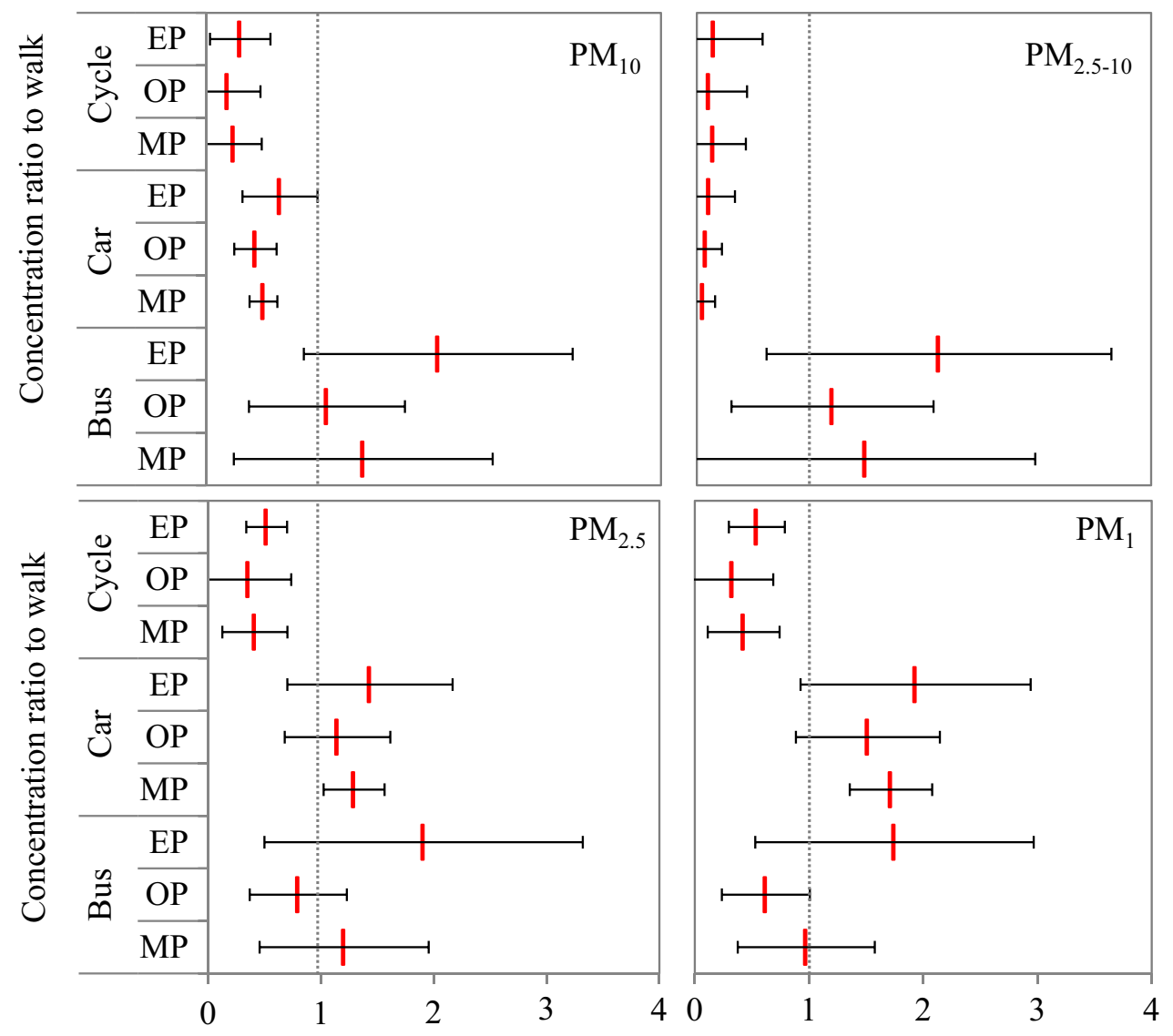

Fig. 4 Normalised (with respect to walk mode) concentrations of different-sized PM in various TMEs assessed in this study. The error bars represent minimum and maximum values of the average ratios

walk mode to assess differences between the transport modes. $\mathrm{PM}_{10}, \mathrm{PM}_{2.5-10}, \mathrm{PM}_{2.5}$ and $\mathrm{PM}_{1}$ concentrations were significantly lower for cycle mode compared to the walk mode (Fig. 4). In the car mode, during all three observation periods (i.e., MP, OP and $E P)$, the total $\mathrm{PM}_{10}$ and coarse particles concentrations were low, but the average concentrations of fine and submicron $\left(\mathrm{PM}_{1}\right)$ particles were higher compared to walk mode (Fig. 4). In this regard, commuting in cars could be more harmful than by walk from the viewpoint of exposure to fine and $\mathrm{PM}_{1}$, which can penetrate deeper into the bronchiole and alveoli regions and cause adverse health effects. Compared to walk, bus concentrations were approximately comparable for all size ranges for OP and approximately twice as high for EP, with MP values closer to OP than EP.

As compared to the walk mode higher levels of coarse particles were observed in the buses, while higher concentrations of fine and submicron particles were observed in the cars and, sometimes, also in the buses. The cycle mode had the lowest average levels of $\mathrm{PM}_{1}, \mathrm{PM}_{2.5}$ and $\mathrm{PM}_{10}$. Fine particle abundance in vehicle modes, including car and bus, compared to walk mode is consistent with earlier observations of a higher in-vehicle versus walk exposure concentrations in Central London. ${ }^{51}$ However, the fine particle concentration ratio for cycle versus walk mode of only 0.41 is much lower than a ratio of 1.2 reported from Central London, presumably due to street canyon effects compared with mostly open road conditions in our study. ${ }^{51}$ In the highly polluted city of Delhi (India), the mass ratios of fine particles between modes were 1.5 for cycle-to-walk, 0.3 for car-to-walk and 0.9 for bus-to-walk. ${ }^{52}$

Concentrations of $\mathrm{PM}_{2.5-10}$ as compared to $\mathrm{PM}_{2.5}$ were relatively high in the bus and walk modes (SI Fig S3). The average mass concentration ratio of $\mathrm{PM}_{2.5-10} / \mathrm{PM}_{2.5}$ in bus mode varied from 1.6 to 3.0 , whereas in walk mode it ranged from 1.4 to 2.0 , as high as by a factor of 2 to 3 (SI Fig S3). Conversely, $\mathrm{PM}_{2.5}$ predominates in the car and cycle modes: $\mathrm{PM}_{2.5-10} / \mathrm{PM}_{2.5}$ in cars ranged from 0.05 to 0.1 (i.e., 5 to $10 \%$ of fine particles), whereas it varied from $\sim 0.4$ to 0.55 on cycle mode (i.e., 40 to $55 \%$ ). Re-suspension effect appears to be the main cause for elevated levels of coarse particles in the bus and in walk modes.

\section{Exposure assessment}

RDD account for differences in physical activity and the time spent in a microenvironment. ${ }^{53,54}$ We estimated RDD for both fine and coarse particles using inhalation rates for males (Fig. 5) and females (SI Fig S4). Since the trend of results for male and female RDD are similar, the discussion in the subsequent text are valid for both genders. Here we only refer to male doses in the discussion for the brevity reasons. The RDD for coarse particles (Fig. 5a) were the highest during the walk mode, with mean RDD ranging from 40 to $66 \mu \mathrm{g} \mathrm{h}^{-1}$ among the MP, OP and EP periods. These were followed by buses $\left(28-32 \mu \mathrm{g} \mathrm{h}^{-1}\right)$, cycle $\left(10-15 \mu \mathrm{g} \mathrm{h}^{-1}\right)$ and cars $\left(0.8-1.3 \mu \mathrm{g} \mathrm{h}^{-1}\right)$. However, fine particle-based RDD were comparable for walk $\left(5-6 \mu \mathrm{gh}^{-1}\right)$ and cycle $\left(4-6.5 \mu \mathrm{gh}^{-1}\right)$ and were higher than for bus $\left(3.5-5 \mu \mathrm{g} \mathrm{h}^{-1}\right)$ and car $\left(1.8-2 \mu \mathrm{g} \mathrm{h}^{-1}\right)$ modes. The fine particle-based RDD for walk mode were comparable to that reported by Kumar and Goel ${ }^{37}$ for the same study area $(7 \mu \mathrm{g}$ $\mathrm{h}^{-1}$ ). Likewise, Rivas et al. ${ }^{42}$ reported that mean PM 2.5 -based RDD decreased when comparing walk to bus and car modes. A Barcelona-based study also found that walk and cycle modes had similar RDD, with walk at $6.8 \mu \mathrm{gh}^{-1}$ and cycle at $6.7 \mu \mathrm{g} \mathrm{h}^{-1}$, and that RDD were lower for bus $\left(5.4 \mu \mathrm{gh}^{-1}\right)$ and car $\left(5.6 \mu \mathrm{gh}^{-1}\right)$ modes. $^{8}$ 

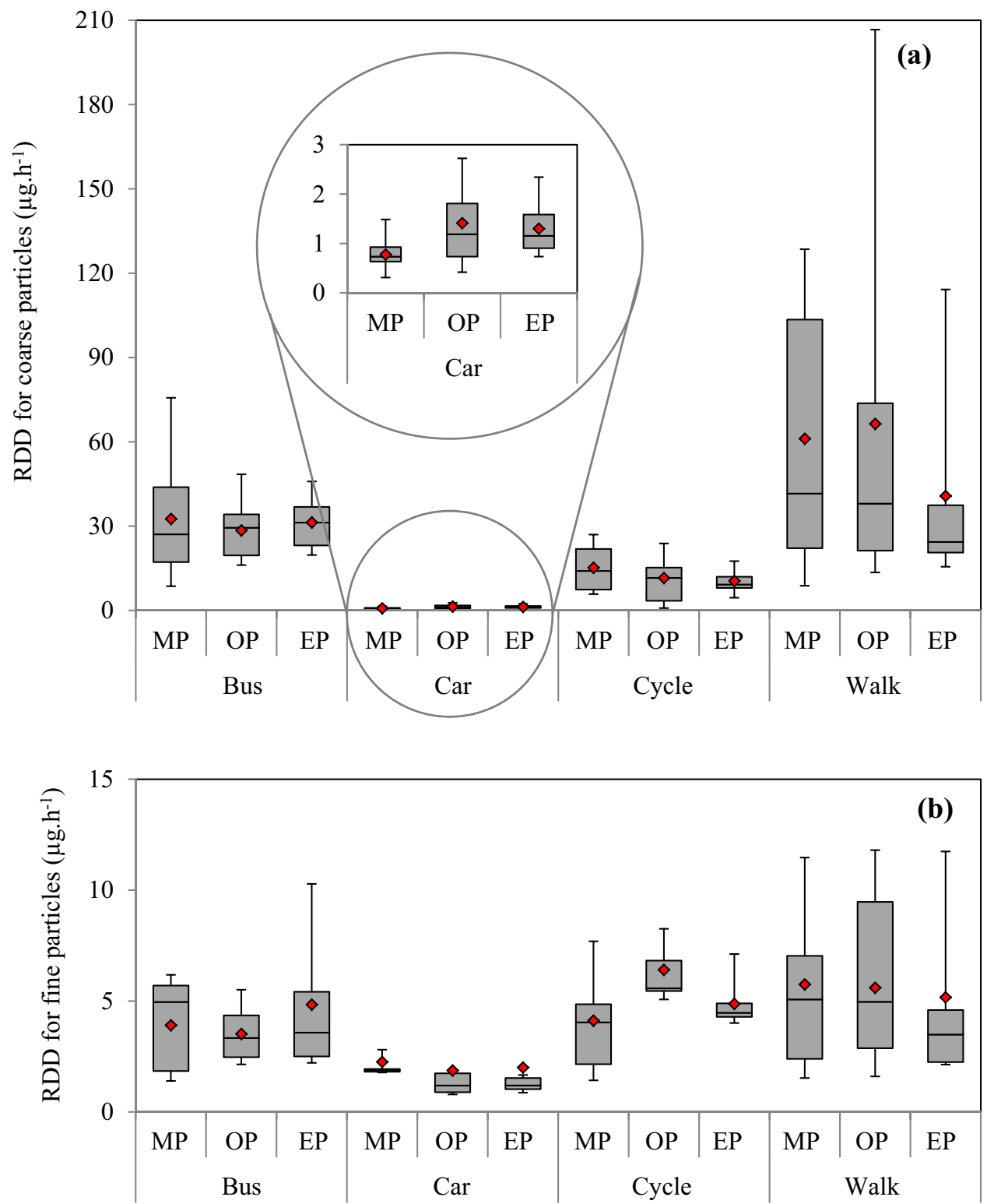

Fig. 5 Estimated RDD for a coarse and $\mathbf{b}$ fine particles for males during sitting (bus and car), heavy exercise (cycling) and light exercise (walk). The whiskers in the figure represent 5th and 95th percentiles, whereas the box plot represents for 25th, 50th (median) and 75th percentiles. The arithmetic mean for the data is represented by diamond symbols

Relative to fine particles, the mean RDD for coarse particles were $8-12,6.5-8.3$ and 1.8-3.7 times higher during walk, bus and cycle modes, respectively, but only between 0.3 and 0.8 for car mode. This shows the effect of traffic-related sources such as resuspension in the walk, bus and cycle modes while the in-car exposure to coarse particles is hindered by the closed windows and the filtration system. The difference in RDD between coarse and fine particles can be explained by the difference in fine and coarse PM mass concentrations, particle mean diameter and sizedependent deposition fractions (DFs).

The RDD were lowest for cars among all modes for both particle size ranges and for all three time periods. Recently, Rivas et al. ${ }^{42}$ reported that $\mathrm{PM}_{2.5}$-based $\mathrm{RDD}$ follows a similar trend to that found herein that RDD are the highest for walk $(4.9 \pm 1.0 ; 3.7-6.1$ $\left.\mu \mathrm{g} \mathrm{h}^{-1}\right)$ and is smaller for bus $\left(2.7 \pm 1.1 ; 1.9-4.3 \mu \mathrm{g} \mathrm{h}^{-1}\right)$ and smallest for car $\left(1.0 \pm 0.2 ; 0.7-1.2 \mu \mathrm{gh}^{-1}\right)$. A Barcelona study reported a nearly similar trend when comparing $\mathrm{PM}_{2.5}$-based average RDD among the modes: walk $\left(6.8 \mu \mathrm{gh}^{-1}\right) \approx \operatorname{cycle}(6.7 \mu \mathrm{g}$ $\left.\mathrm{h}^{-1}\right)>$ bus $\left(5.4 \mu \mathrm{g} \mathrm{h}^{-1}\right) \approx \operatorname{car}\left(5.6 \mu \mathrm{g} \mathrm{h}^{-1}\right) .^{8}$ Although cars show the lowest personal doses among all the transport modes studied, it should be highlighted that they have the highest emission per passenger. Therefore, the contribution of private transportation is actually leading to an increased exposure and dose of those commuters choosing an environmental-friendly commuting options such as cycling and walking.

\section{DISCUSSION}

The comparison of fine and coarse particles exposure concentrations among transport modes and for different times of day showed that:

- For coarse particles, exposure concentrations were lower for cyclists than for pedestrians or occupants of cars or buses, for all three times of day that were measured. The highest coarse particle exposures were in buses for all three times of the day. There was substantial inter-run variability. Many runs are needed to develop a statistically stable estimate of mean 
exposure concentrations. A higher infiltration of outside pollutants into the buses through the frequent opening of their doors and accumulation of particles can be attributed to this trend. A close proximity of pedestrians with the traffic exhaust emissions and likely re-suspension of mineral dust particles lead to high coarse particle exposure during walk mode. The larger-sized particles are likely to be restricted in car cabins if windows are kept closed to prevent infiltration and by the car filtering system, hence resulting in reduced exposure concentrations.

- For fine particles, the average concentrations of $\mathrm{PM}_{2.5}$ in closed transport modes (car and bus) were higher than those in open active travel modes (cycle and walk) due to their shorter distance to the source as well as the accumulation of particles within the vehicles (especially in the car mode, where fine particles get inside the cabin through mechanical ventilation by their dispersion is then hindered by the closed windows). The cycle mode also had the lowest average concentrations. However, there was more variability in the rank ordering of exposure among the transport modes based on time of day. For example, pedestrian exposures were much lower during the EP than during the MP or OP periods. Bus exposure concentrations were higher than for other transport modes in the MP and EP, but lower than for car and pedestrian in OP. Some of the variability among modes with regard to time of day may be because of operational factors (e.g., numbers of passengers boarding and alighting from the bus), traffic flow, traffic-induced turbulence and mixing of vehicle-emitted pollutants, and others are related to meteorological factors (e.g., atmospheric stability). The trend in exposure to $\mathrm{PM}_{1}$ among modes and times of day is usually similar to that for $\mathrm{PM}_{2.5}$.

The assessment of the real-time RDD of fine and coarse particles during peak and OP periods showed that:

- Pedestrians are estimated to have the highest RDD for coarse particles. Cyclists have much lower RDD than pedestrians or those riding buses, but higher than those in cars. As for fine particles, RDD are approximately equally high for pedestrians and cyclists, an approximately $20 \%$ higher than for bus passengers and 2.5 times higher than for car occupants (if windows are closed and AC is on).

- For coarse particles, the rank ordering of RDD is different than the rank ordering of exposure concentrations. Pedestrians and cyclists have higher breathing rates than do occupants of cars and buses. Thus, even though buses have the highest average exposure concentrations for all times of day, the highest RDD are for pedestrians for all times of the day. Similarly, for fine particles, pedestrians and cyclists have high RDD even though their exposure concentrations are lower than for the motorised transport modes.

The identification of the factors that influenced the temporal variability of particles in different TMEs indicated that:

- Management of commuting exposures should consider potential dose, such as RDD, and not just exposure concentration, to help reduce adverse health effects from air pollution related to commuting.

- Although there is variability in both exposure and RDD with respect to time of day, the differences in both exposure and RDD between transport modes tend to be larger than the differences within a mode related to the time of the day. Thus, choices of modes to minimise either exposure or RDD can be relatively robust to the time of the day. For example, for both coarse and fine particles, the car mode had the lowest RDD for each of the three measured times of day. However, it is worth mentioning that private car commutes contribute to the highest emissions per passenger, thus contributing to increased exposure of those commuting using cleaner modes (such as cycle and walk).

- There are sources of variability established in prior work ${ }^{37}$ that was not the focus of quantification here, such as the role of opening vehicle windows or operating the vehicle HVAC system with fresh air intake versus recirculating air. Choices of these ventilation practices can lead to substantial changes in bus and car exposure concentration.

- Although RDD for pedestrian and cycle modes were not the lowest among the four measured modes, there are opportunities to reduce RDD for these modes by reducing exposure concentrations. Pedestrian and cyclist exposures could be further reduced by routing pedestrian and cycling paths away from heavily trafficked roadways. Such a change would require that urban planning incorporate a goal of separating pedestrians and cyclists from vehicle traffic when designing paths and roads.

Our study showed that the exposure concentrations vary depending on the choice of a mode. Fresh fumes from the tailpipe emissions result in commuters' exposure to frequent transient peaks in near-road environments. ${ }^{12,47}$ Therefore, further studies are recommended to estimate the exposure concentrations based on shorter averaging time for specific segments of the route, to enable quantification of spatial variability in exposure concentrations. Alternative routes between a particular origin and destination pair could be measured to assess whether exposure concentrations in a given mode are sensitive to route choice. Measurements could also be made in other seasons, such as summer, to assess seasonal variability. Routes for walk and cycle could be specified to keep pedestrians and cyclists as far from major thoroughfares as possible, to assess by how separation from traffic could lead to lower exposures. The design of future studies should consider the micro-assessment of route characteristics such as getting on/off the buses, effect of de-routing of cyclists or pedestrians to quieter routes and the effect of sampling heights. Such studies could also consider quantification of metals and polycyclic aromatic hydrocarbons in aerosol particles to allow risk assessment due to these toxic species.

\section{METHODS}

Route characteristics

TME exposure concentrations were measured in the town of Guildford (UK). Guildford has a total population of 130000 , is situated $50 \mathrm{~km}$ southwest of London and has a maritime climate. On average, each household owns about two cars, which is more than the national average. ${ }^{55}$ Commuting exposures are compared for four travel modes, including car, cycle, walk (hereafter referred to as the CCW) and bus modes, based on strategically selected routes. As shown in Fig. 6, a $5.3 \mathrm{~km}$ route was used for CCW routes, whereas a different $13.8 \mathrm{~km}$ route was selected for the bus mode. The CCW and bus routes have $1.6 \mathrm{~km}$ in common (Fig. 6). The CCW route is shorter than the bus route so that walk mode can be completed during a peak period. Both routes are circular closed loops and include a variety of road type and land use patterns.

\section{Description of travel modes}

To assess the variability in exposure among different times of the day, measurements were made during MP (0830-1100 hours; local time), afternoon OP (1300-1500 hours) and EP (1700-1900 hours). All measurements were made on weekdays. The respective sunrise and sunset times during the measurement periods were $0538-0740$ and $1651-2021$ hours, respectively, with a total day length varying between 0910 and 1441 hours. ${ }^{56}$ The average trip time to complete a CCW route run by car was $17 \mathrm{~min}$ while it was $18 \mathrm{~min}$ by cycle, and $80 \mathrm{~min}$ by walk. A single run on the bus route typically took $50 \mathrm{~min}$ to complete (Table 3 ). The differences in travel time by each of these modes arise because of differences in speed and route length. The car (model: Vauxhall Corsa SXi, 2014) measurements were performed in traffic and represent typical driving. During all the runs, the car windows were closed and the air 


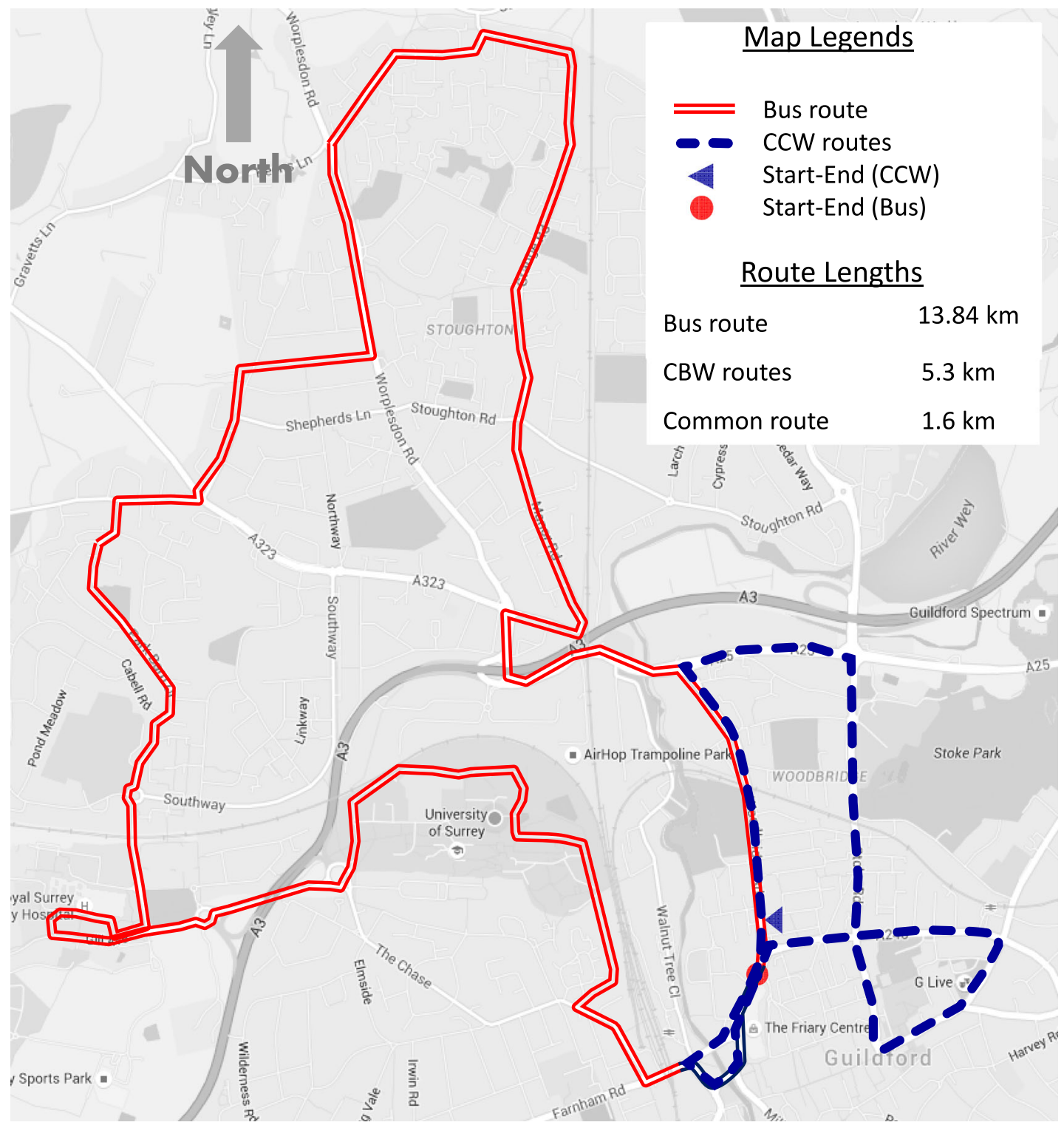

Fig. 6 Description of routes followed by the bus and CCW (car, cycle and walk) modes. The background map is drawn over the image taken from Map data $\odot 2017$ Google

\begin{tabular}{|llllll|}
\hline \multicolumn{2}{l}{ Table 3. Characteristics and number of trips of the routes covered by different travel modes } \\
\hline Mode of travel & Route length $(\mathrm{km})$ & Average time \pm SD $(\mathrm{min})$ & \multicolumn{2}{l|}{ Total time for collected data in minutes (number of trips) } \\
\cline { 3 - 6 } & & & Morning peak & Off-peak & Evening peak \\
\hline Bus & 13.84 & $50.2 \pm 6.6$ & $478(10)$ & $484(10)$ & $544(10)$ \\
Car & 5.3 & $17.0 \pm 2.2$ & $245(15)$ & $350(21)$ & $287(16)$ \\
Cycle & 5.3 & $17.5 \pm 2.1$ & $170(10)$ & $177(10)$ & $178(10)$ \\
Walk & 5.3 & $79.9 \pm 20.4$ & $813(10)$ & $858(10)$ & $725(10)$ \\
\hline SD standard deviation & & & & \\
\end{tabular}

conditioning was kept on with air intake from outside. The buses were mostly fuelled with diesel. In the buses, air conditioning was in use and windows were closed, except for a partially opened window near the driver. Table 3 shows the summary of route lengths and travel times for each mode. Monitoring by cycling and walk modes was performed at normal cycling and walking speeds.

\section{Instrumentation}

A GRIMM optical particle spectrometer (OPC; model 1.107) was used to measure the mass distribution of PM in the size range from 0.25 to $32 \mu \mathrm{m}$ following the principle of light scattering. The lower size cutoff of $0.25 \mu \mathrm{m}$ means that these quasi-ultrafine particles are not measured. However, these particles contains negligible mass compared with their larger 
counterparts and hence have a modest effect on measured mass concentrations. ${ }^{6}$ The sensitivity of the instrument was $1 \mu \mathrm{g} \mathrm{m}^{-3}$ and reproducibility were within $\pm 2 \%$. Ambient air was drawn continuously at a flow rate of $1.2 \mathrm{~L} \mathrm{~min}^{-1}$ into the OPC and size-resolved PM concentrations were recorded every $6 \mathrm{~s}$. The instrument was calibrated by the manufacturer prior to the deployment in field work. Following our previously used approach, ${ }^{57}$ we also carried out on-site calibration by weighing the polytetrafluoroethylene filters used at the back of the instrument and compared it with the data of PM mass monitored by the instrument. The instruments were kept inside an open shoulder bag while walking and cycling, at the passenger front seat while commuting by car, and at the centre row when commuting by bus. Meteorological data were retrieved from a nearby Heathrow airport station. ${ }^{58}$ The average wind speed, ambient temperature and relative humidity ( \pm standard deviation) were $10 \pm 4 \mathrm{~km} \mathrm{~h}^{-1}, 13 \pm 5^{\circ} \mathrm{C}$ and $62 \pm 8 \%$, respectively.

\section{Data collection and analysis}

Measurements were made during February to April 2015. Real-time exposure concentrations for $\mathrm{PM}_{1}, \mathrm{PM}_{2.5}$ and $\mathrm{PM}_{10}$ were measured for four TMEs (bus and CCW modes) during MP, OP and EP. A total of 142 round trips were made; of which 30 trips were carried out by bus, 52 by car, 30 by cycle and 30 by walk (Table 3 ). The details on the number of trips and sampling dates for the different TMEs are given in SI Table S1. The typical average speed varied by mode. The total time invested in air monitoring was $88 \mathrm{~h}$ and $29 \mathrm{~min}$ (Table 3).

\section{Respiratory lung deposition doses}

RDD were estimated for each PM fraction according to the approach used in our earlier work. ${ }^{37,59}$ The RDD largely depend on the shape, size, mass and density of the particles ${ }^{60}$ and are estimated based on the International Commission on Radiological Protection ${ }^{61}$.

$\mathrm{RDD}$ of $\mathrm{PM}($ fractions,$i)=\left(V_{\mathrm{T}} \times f\right) \times \mathrm{DF}_{i} \times \mathrm{PM}_{i}$

$$
\left[\mu \mathrm{g} \mathrm{s}^{-1}\right]=\left[\mathrm{cm}^{3} \text { breath }^{-1} \times \text { breaths s }^{-1}\right] \times[-] \times\left[\mu \mathrm{g} \mathrm{cm}^{-3}\right]
$$

where $V_{\mathrm{T}}$ is the tidal volume of human subjects. This was taken as 750 (460), 1920 (1360) and 1250 (990) $\mathrm{cm}^{3}$ per breath and during sitting condition (for bus and car), heavy (for cycle) and light (for walk) exercises, respectively, for adult males (females, shown by values within the brackets). ${ }^{22}$ The variable $f$ represents typical breathing frequency, which is taken as $0.43(0.55), 0.33(0.35)$ and $0.20(0.23)$ breaths per second during heavy exercise, light exercise and sitting, respectively, for males (females). ${ }^{22} \mathrm{DF}_{i}$ are estimated using mass median diameter $\left(d_{\mathrm{p}}\right)$ of PM for each size bin. ${ }^{22}$ The $d_{\mathrm{p}}$ represents optical diameter that would be different to aerodynamic diameter, ${ }^{62}$ especially for coarse particles that contains irregular shapes and varying density. ${ }^{63}$ For example, Chien et al. ${ }^{62}$ confirms that the optical diameter is affected by refractive index and morphology and hence the relationships between optical and aerodynamic diameters could be different for pure substances such as salt or oleic acid particles than those for the complex mixture of particles measured here. This difference will add uncertainty into the calculated DFs, from modest to more than a factor of two in equivalent aerodynamic diameter and deposition fraction for some TMEs, as demonstrated in Supplementary Information (SI) Figure S1. We have not made conversion to ensure that our estimates are comparable with published studies, using optical diameter during mobile personal exposure measurements. Since we were required to make numerous assumptions due to lack of specific information, we have not considered the hygroscopic properties ${ }^{64}$ of the particles for estimating the lung DFs. For the calculation of the $d_{\mathrm{p}}$ we calculated the mass concentrations of each size bin and, afterwards, we plotted the percentage of cumulative mass concentration to each size bin (i.e., the addition of the mass concentration of the corresponding size bin and the mass concentration of all bins of smaller sizes). The DF is calculated according to the following equation:

$$
\begin{gathered}
\mathrm{DF}=\mathrm{IF}\left(0.058+\frac{0.911}{1+\exp \left(4.77+1.485 \ln d_{\mathrm{p}}\right)}\right. \\
\left.+\frac{0.943}{1+\exp \left(0.508-2.58 \ln d_{\mathrm{p}}\right)}\right)
\end{gathered}
$$

SI Figure S2 shows the approach used to calculate $d_{\mathrm{p}}$ for $\mathrm{PM}_{10}, \mathrm{PM}_{2.5}$ and $\mathrm{PM}_{1}$. IF is the inhalable fraction:

$\mathrm{IF}=1-0.5\left(1-\frac{1}{1+0.00076 d_{\mathrm{p}}^{2.8}}\right)$

The resulting product of various parameters in Eq. (1), including the $V_{T}, f$ and DF with $\mathrm{PM}_{2.5-10}$ or $\mathrm{PM}_{2.5}$ mass concentrations represents the massspecific RDD due to coarse and fine particles, respectively. We have chosen to estimate RDD as mass per unit time $\left(\mu \mathrm{g} \mathrm{s}^{-1}\right)$ for comparison purposes across different microenvironments on a time basis. It also allows to calculate total mass deposited in each microenvironment by multiplying RDD by time spent in a TME.

Data availability

The data sets used in this study are available upon request from the corresponding author.

\section{ACKNOWLEDGEMENTS}

P.K. and H.C.F. acknowledge the funding received from the University Global Partnership Network (UGPN) through the project-Comparison of Air Pollution in Transportation Environments (CAPTEN): Development and Demonstration Based on Selected UK and US Cities-for supporting this research work. The authors thank Disha Gadre, Vee Bahat and Anju Goel for their help in data collection and Prashant Rajput for suggesting preliminary text on some figures. P.K. also thanks the funding received from to the iSCAPE (Improving Smart Control of Air Pollution in Europe) project through the European Community's H2020 Programme under the Grant Agreement No. 689954.

\section{AUTHOR CONTRIBUTIONS}

P.K. and H.C.F. conceptualised and designed the study; they both assisted in data collection, interpreted results and wrote the manuscript. I.R. contributed to the preliminary draft of the article. A.P.S. and M.A. contributed to data analysis and preparing some of the figures. V.J.G. assisted in data collection, its indexing, generating route map and preliminary text for methodology sections.

\section{ADDITIONAL INFORMATION}

Supplementary Information accompanies the paper on the npj Climate and Atmospheric Science website (https://doi.org/10.1038/s41612-018-0023-y).

Competing interests: The authors declare no competing interests.

Publisher's note: Springer Nature remains neutral with regard to jurisdictional claims in published maps and institutional affiliations.

\section{REFERENCES}

1. HEI Panel on the Health Effects of Traffic-Related Air Pollution. Traffic-related Air Pollution: A Critical Review of the Literature on Emissions, Exposure, and Health Effects. HEI Special Report 17. 386 (Health Effects Institute, Boston, 2010).

2. Kumar, P. et al. New directions: air pollution challenges for developing megacities like Delhi. Atmos. Environ. 122, 657-661 (2015)

3. Guerreiro, C. B. B., Foltescu, V. \& de Leeuw, F. Air quality status and trends in Europe. Atmos. Environ. 98, 376-384 (2014).

4. Kumar, P. et al. New Directions: can a "blue sky" return to Indian megacities? Atmos. Environ. 71, 198-201 (2013).

5. Knibbs, L. D., Cole-Hunter, T. \& Morawska, L. A review of commuter exposure to ultrafine particles and its health effects. Atmos. Environ. 45, 2611-2622 (2011).

6. Goel, A. \& Kumar, P. A review of fundamental drivers governing the emissions, dispersion and exposure to vehicle-emitted nanoparticles at signalised traffic intersections. Atmos. Environ. 97, 316-331 (2014).

7. Zuurbier, M. et al. Commuters' exposure to particulate matter air pollution is affected by mode of transport, fuel type, and route. Environ. Health Perspect. 118, 783-789 (2010).

8. de Nazelle, A. et al. A travel mode comparison of commuters' exposures to air pollutants in Barcelona. Atmos. Environ. 59, 151-159 (2012).

9. Int Panis, L. et al. Exposure to particulate matter in traffic: A comparison of cyclists and car passengers. Atmos. Environ. 44, 2263-2270 (2010). 
10. Goel, A. \& Kumar, P. Characterisation of nanoparticle emissions and exposure at traffic intersections through fast-response mobile and sequential measurements. Atmos. Environ. 107, 374-390 (2015).

11. AQEG. Particulate matter in the UK: summary. Defra, London. https://uk-air.defra. gov.uk/assets/documents/reports/aqeg/pm-summary.pdf (2005)

12. Heal, M. R., Kumar, P. \& Harrison, R. M. Particles, air quality, policy and health. Chem. Soc. Rev. 41, 6606-6630 (2012).

13. Zheng, J. et al. Spatial distributions and chemical properties of PM2.5 based on 21 field campaigns at 17 sites in China. Chemosphere 159, 480-487 (2016).

14. Monkkonen, P. et al. Relationship and variations of aerosol number and PM10 mass concentrations in a highly polluted urban environment-New Delhi, India. Atmos. Environ. 38, 425-433 (2004).

15. WHO. Air Quality Guidelines for Particulate Matter, Ozone, Nitrogen Dioxide and Sulfur Dioxide. 22. http://apps.who.int/iris/bitstream/10665/69477/1/WHO_SDE_PHE_OEH_06.02_eng.pdf (2005).

16. Review of evidence on health aspects of air pollution-REVIHAAP. World Health Organisation, Regional Office for Europe. 33. http://www.euro.who.int/_ data/ assets/pdf_file/0020/182432/e96762-final.pdf (2013).

17. Bos, I. et al. No exercise-induced increase in serum BDNF after cycling near a major traffic road. Neurosci. Lett. 500, 129-132 (2011).

18. Jacobs, L. et al. Subclinical responses in healthy cyclists briefly exposed to trafficrelated air pollution. Environmen. Health 9, 64 (2010).

19. Bhatnagar, A. Environmental cardiology: studying mechanistic links between pollution and heart disease. Circ. Res. 99, 692-705 (2006).

20. Lim, S. S. et al. A comparative risk assessment of burden of disease and injury attributable to 67 risk factors and risk factor clusters in 21 regions, 1990-2010: a systematic analysis for the Global Burden of Disease Study 2010. Lancet 380, 2224-2260 (2012).

21. Loomis, D. et al. International Agency for Research on Cancer Monograph Working Group IARC. Lancet Oncol. 14, 1262-1263 (2013).

22. Hinds, W. C. Aerosol Technology: Properties, Behaviour and Measurement of Airborne Particles 483 (John Wiley \& Sons, UK, 1999).

23. Briggs, D. J., de Hoogh, K., Morris, C. \& Gulliver, J. Effects of travel mode on exposures to particulate air pollution. Environ. Int. 34, 12-22 (2008).

24. Kaur, S., Nieuwenhuijsen, M. J. \& Colvile, R. N. Fine particulate matter and carbon monoxide exposure concentrations in urban street transport microenvironments. Atmos. Environ. 41, 4781-4810 (2007).

25. Goel, A. \& Kumar, P. Zone of influence for particle number concentrations at signalised traffic intersections. Atmos. Environ. 123, 25-38 (2015).

26. Morawska, L., Ristovski, Z., Jayaratne, E. R., Keogh, D. U. \& Ling, X. Ambient nano and ultrafine particles from motor vehicle emissions: Characteristics, ambient processing and implications on human exposure. Atmos. Environ. 42, 8113-8138 (2008).

27. Moreno, T. et al. Urban air quality comparison for bus, tram, subway and pedestrian commutes in Barcelona. Environ. Res. 142, 495-510 (2015).

28. Unal, A., Frey, H. C. \& Rouphail, N. M. Quantification of highway vehicle emissions hot spots based upon on-board measurements. J. Air Waste Manag. Assoc. 54, 130-140 (2012)

29. de Hartog, J. J., Boogaard, H., Nijland, H. \& Hoek, G. Do the health benefits of cycling outweigh the risks? Environ. Health Perspect. 118, 1109-1116 (2010).

30. Huang, J., Deng, F., Wu, S. \& Guo, X. Comparisons of personal exposure to $\mathrm{PM}_{2.5}$ and $\mathrm{CO}$ by different commuting modes in Beijing, China. Sci. Total Environ. 425 52-59 (2012)

31. Cole-Hunter, T., Morawska, L., Stewart, I., Jayaratne, R. \& Solomon, C. Inhaled particle counts on bicycle commute routes of low and high proximity to motorised traffic. Atmos. Environ. 61, 197-203 (2012)

32. Hankey, S. \& Marshall, J. D. On-bicycle exposure to particulate air pollution: particle number, black carbon, PM2.5, and particle size. Atmos. Environ. 122, 65-73 (2015)

33. McNabola, A., Broderick, B. M. \& Gill, L. W. A numerical investigation of the impact of low boundary walls on pedestrian exposure to air pollutants in urban street canyons. Sci. Total Environ. 407, 760-769 (2009).

34. Adams, H. S., Nieuwenhuijsen, M. J., Colvile, R. N., Older, M. J. \& Kendall, M. Assessment of road users' elemental carbon personal exposure levels, London, UK. Atmos. Environ. 36, 5335-5342 (2002).

35. Tainio, M. et al. Can air pollution negate the health benefits of cycling and walking? Prev. Med. 87, 233-236 (2016).

36. Joodatnia, P., Kumar, P. \& Robins, A. Fast response sequential measurements and modelling of nanoparticles inside and outside a car cabin. Atmos. Environ. 71, 364-375 (2013).

37. Kumar, P. \& Goel, A. Concentration dynamics of coarse and fine particulate matter at and around the signalised traffic intersections. Environ. Sci. Process. Impact 18, 1220-1235 (2016).

38. Mkoma, S. L. et al. Major ions in $\mathrm{PM}_{2.5}$ and $\mathrm{PM}_{10}$ released from buses: the use of diesel/biodiesel fuels under real conditions. Fuel 115, 109-117 (2014).
39. Chio, C.-P., Cheng, Y.-H., Ling, M.-P., Chen, S.-C. \& Liao, C.-M. Quantitative estimation of excess mortality for drivers and passengers exposed to particulate matters in long-distance buses. Atmos. Environ. 51, 260-267 (2012).

40. Wang, J. et al. Characteristics of particulate matter (PM) concentrations influenced by piston wind and train door opening in the Shanghai subway system. Transp. Res. Part D Transp. Environ. 47, 77-88 (2016).

41. Jaffe, D. et al. Diesel particulate matter and coal dust from trains in the Columbia River Gorge, Washington State, USA. Atmos. Pollut. Res. 6, 946-952 (2015).

42. Rivas, I., Kumar, P. \& Hagen-Zanker, A. Exposure to air pollutants during commuting in London: are there inequalities among different socio-economic groups? Environ. Int. 101, 143-157 (2017).

43. Peters, J. et al. Cyclist exposure to UFP and BC on urban routes in Antwerp, Belgium. Atmos. Environ. 92, 31-43 (2014).

44. Schepers, P. et al. The mortality impact of bicycle paths and lanes related to physical activity, air pollution exposure and road safety. J. Transp. Health 2 460-473 (2015)

45. Gulliver, J. \& Briggs, D. J. Personal exposure to particulate air pollution in transport microenvironments. Atmos. Environ. 38, 1-8 (2004).

46. Hudda, N. et al. Linking in-vehicle ultrafine particle exposures to on-road concentrations. Atmos. Environ. 59, 578-586 (2012).

47. Goel, A. \& Kumar, P. Vertical and horizontal variability in airborne nanoparticles and their exposure around signalised traffic intersections. Environ. Pollut. 214 54-69 (2016).

48. Kumar, P., Fennell, P., Langley, D. \& Britter, R. Pseudo-simultaneous measurements for the vertical variation of coarse, fine and ultra fine particles in an urban street canyon. Atmos. Environ. 42, 4304-4319 (2008).

49. Kumar, P., Rivas, I. \& Sachdeva, L. Exposure of in-pram babies to airborne particles during morning drop-in and afternoon pick-up of school children. Environ. Pollut. 224, 407-420 (2017)

50. Joodatnia, P., Kumar, P. \& Robins, A. The behaviour of traffic produced nanoparticles in a car cabin and resulting exposure rates. Atmos. Environ. 65, 40-51 (2013).

51. Kaur, S., Nieuwenhuijsen, M. \& Colvile, R. Personal exposure of street canyon intersection users to PM2.5, ultrafine particle counts and carbon monoxide in Central London, UK. Atmos. Environ. 39, 3629-3641 (2005).

52. Goel, R., Gani, S., Guttikunda, S. K., Wilson, D. \& Tiwari, G. On-road PM 2.5 pollution exposure in multiple transport microenvironments in Delhi. Atmos. Environ. 123 (Part A), 129-138 (2015).

53. Tunno, B. J. et al. Indoor source apportionment in urban communities near industrial sites. Atmos. Environ. 139, 30-36 (2016).

54. Franzen, A., Van Landingham, C., Greene, T., Plotzke, K. \& Gentry, R. A global human health risk assessment for Decamethylcyclopentasiloxane (D5). Regul. Toxicol. Pharm. 74, S25-S43 (2016).

55. Census in Surrey, data collection-census household characteristics: car availability. $C=$ resource\&ResourcelD $=1054$ (2011)

56. Sun rise and sun set in Guildford. http://www.sunrise-and-sunset.com/en/sun/ united-kingdom/guildford/2015/april. (2015)..

57. Ramos, M. J., Vasconcelos, A. \& Faria, M. Comparison of particulate matter inhalation for users of different transport modes in Lisbon. Transp. Res. Procedia 10, 433-442 (2015)

58. UK met office. http://www.metoffice.gov.uk/datapoint. (2016)

59. Azarmi, F. \& Kumar, P. Ambient exposure to coarse and fine particle emissions from building demolition. Atmos. Environ. 137, 62-79 (2016).

60. Tsuda, A., Henry, F. S. \& Butler, J. P. Particle transport and deposition: basic physics of particle kinetics. Compr. Physiol. 3, 1437-1471 (2013).

61. ICRP publication 66: human respiratory tract model for radiological protection. $A$ Report of a Task Group of the International Commission on Radiological Protection. 1-482. http://www.icrp.org/publication.asp?id=icrp\%20publication\%2066 (1994).

62. Chien, C. H., Theodore, A., Wu, C. Y., Hsu, Y. M. \& Birky, B. Upon correlating diameters measured by optical particle counters and aerodynamic particle sizers. J. Aerosol Sci. 101, 77-85 (2016).

63. Sanders, P. G., Xu, N., Dalka, T. M. \& Maricq, M. M. Airborne brake wear debris: size distributions, composition, and a comparison of dynamometer and vehicle tests. Environ. Sci. Technol. 37, 4060-4069 (2003).

64. Vu, T. V. et al. Physical properties and lung deposition of particles emitted from five major indoor sources. Air Qual. Atmos. Health 10, 1-14 (2017).

65. Li, Z., Che, W., Frey, H. C., Lau, A. K. H. \& Lin, C. Characterization of PM2.5 exposure concentration in transport microenvironments using portable monitors. Environ. Pollut. 228, 433-442 (2017).

66. Che, W. W., Frey, H. C. \& Lau, A. K. H. Sequential measurement of intermodal variability in public transportation $\mathrm{PM}_{2.5}$ and $\mathrm{CO}$ exposure concentrations. Environ. Sci. Technol. 50, 8760-8769 (2016).

67. Li, B. et al. Personal exposure to black carbon during commuting in peak and offpeak hours in Shanghai. Sci. Total Environ. 524-525, 237-245 (2015). 
68. Liu, W.-T. et al. Effects of commuting mode on air pollution exposure and cardiovascular health among young adults in Taipei, Taiwan. Int. J. Hyg. Environ. Health 218, 319-323 (2015).

69. Jiao, W. \& Frey, C. H. Comparison of fine particulate matter and carbon monoxide exposure concentrations for selected transportation modes. Transp. Res. Rec. J. Transp. Res. Board 2428, 54-62 (2014).

70. Quiros, D. C., Lee, E. S., Wang, R. \& Zhu, Y. Ultrafine particle exposures while walking, cycling, and driving along an urban residential roadway. Atmos. Environ. 73, 185-194 (2013).

71. Kingham, S., Longley, I., Salmond, J., Pattinson, W. \& Shrestha, K. Variations in exposure to traffic pollution while travelling by different modes in a low density, less congested city. Environ. Pollut. 181, 211-218 (2013).

72. $\mathrm{Yu}, \mathrm{Q}$. et al. Commuters' exposure to PM1 by common travel modes in Shanghai. Atmos. Environ. 59, 39-46 (2012).

73. Chan, L. Y., Lau, W. L., Zou, S. C., Cao, Z. X. \& Lai, S. C. Exposure level of carbon monoxide and respirable suspended particulate in public transportation modes while commuting in urban area of Guangzhou, China. Atmos. Environ. 36, 5831-5840 (2002)

74. Adams, H. S., Nieuwenhuijsen, M. J., Colvile, R. N., McMullen, M. A. S. \& Khandelwal, P. Fine particle $\left(\mathrm{PM}_{2.5}\right)$ personal exposure levels in transport microenvironments, London, UK. Sci. Total Environ. 279, 29-44 (2001).
75. Gee, I. L. \& Raper, D. W. Commuter exposure to respirable particles inside buses and by bicycle. Sci. Total Environ. 235, 403-405 (1999).

(i) Open Access This article is licensed under a Creative Commons Attribution 4.0 International License, which permits use, sharing, adaptation, distribution and reproduction in any medium or format, as long as you give appropriate credit to the original author(s) and the source, provide a link to the Creative Commons license, and indicate if changes were made. The images or other third party material in this article are included in the article's Creative Commons license, unless indicated otherwise in a credit line to the material. If material is not included in the article's Creative Commons license and your intended use is not permitted by statutory regulation or exceeds the permitted use, you will need to obtain permission directly from the copyright holder. To view a copy of this license, visit http://creativecommons. org/licenses/by/4.0/.

(c) The Author(s) 2018 